\title{
PEMBEKALAN DAN PELATIHAN \\ SISWA SMA PLUS PENYABUNGAN MANDAILING NATAL UNTUK MENGHADAPI KOMPETISI SAINS NASIONAL (KSN) KIMIA DENGAN MENGGUNAKAN MODEL PEMBELAJARAN ATM (AMATI, TIRU, MODIFIKASI)
}

\author{
Efrizal Siregar $^{1 *}$, Yusnia Sinambela ${ }^{2}$ \\ ${ }^{1}$ Teknik Grafika, Politeknik Negeri Media Kreatif \\ efrizalsiregarchems@gmail.com, belasinambela@gmail.com
}

\begin{abstract}
ABSTRAK
Abstrak: Kompetisi Sains Nasional (KSN) adalah sebuah ajang kompetisi sains yang dilaksanakan oleh Kementrian Pendidikan dan Kebudayaan Republik Indonesia. KSN yang dilaksanakan pada tingkat SMA ini adalah bidang Kimia yang terintegrasi yang bertujuan untuk meningkatkan kualitas mutu pendidikan dengan mengembangkan secara konprehensif melalui penumbuhkembangan semangat belajar, kreatifitas dan motivasi untuk meraih prestasi. Untuk itu agar dapat mencapai salah satu tujuan KSN yaitu motivasi untuk mencapai prestasi maka sangat diperlukan persiapan dalam menghadapi KSN tersebut. Persiapan yang perlu dilakukan adalah dengan membekali para peserta dengan kemampuan yang baik dalam penguasaan materi dalam hal ini bidang Kimia. Metode pembelajaran yang digunakan adalah model pembelajaran ATM yaitu amati, tiru, dan modifikasi. Tujuan dari pelaksanaan Pembekalan dan Pelatihan dalam menghadapi KSN ini adalah memberikan pengetahuan dan meningkatkan penguasaan materi sehingga siswa siswi khususnya SMA Plus Penyabungan lebih siap dalam mengikuti KSN. KSN yang akan dilaksanakan diharapkan SMA Plus Penyabungan dapat mengirimkan wakilnya ke-Tingkat Nasional dan dapat membawa nama baik SMA Plus Penyabungan secara khusus dan nama baik Sumatera Utara secara Umum.
\end{abstract}

\section{Kata kunci : Pembekalan; Pelatihan; Metode ATM; KSN Kimia}

\begin{abstract}
The National Science Competition (KSN) is a science competition held by the Ministry of Education and Culture of the Republic of Indonesia. KSN which is implemented at the high school level is an integrated field of Chemistry which aims to improve the quality of education by developing it comprehensively through the development of a spirit of learning, creativity and motivation to achieve achievement. For this reason, in order to achieve one of the goals of KSN, namely the motivation to achieve achievement, it is very necessary to prepare in the face of the KSN. The preparation that needs to be done is to equip the participants with good skills in mastering the material, in this case the field of Chemistry. The learning method used is the ATM learning model, namely observing, imitating, and modifying. The purpose of the debriefing and training in dealing with KSN is to provide knowledge and improve mastery of the material so that students, especially SMA Plus Pengabungan are better prepared to take part in KSN. It is hoped that the KSN that will be carried out is expected to be able to send representatives to the National Level Plus SMA Plus Penyebungan and bring the good name of SMA Plus Pengabungan in particular and the good name of North Sumatra in general.
\end{abstract}

Keywords: Debriefing; Training; ATM method; KSN Chemistry

\section{A. LATAR BELAKANG}

Indonesia memiliki sekolah dengan jumlah yang banyak dan potensi siswa yang membanggakan. Minat siswa-siswi di Indonesia ini juga sangat tinggi untuk terlibat dalam kompetensi sains. Akan tetapi, para siswa tersebut tidak di ikuti dengan adanya pembekalan pemahaman tentang sejauh mana sebenarnya persiapan sejak dini dari 
tingkat sekolah yang harus dimiliki oleh siswa tersebut. Banyak siswa peserta KSN khususnya mata lomba kimia memiliki pemahaman materi kimia hanya sebatas kategori pertama yang hanya ada pada buku pelajaran sekolah itupun belum di kembangkan. Mereka sama sekali belum dapat pengetahuan kimia pada kategori kedua dan ketiga dikarenakan informasi yang diterima siswa di daerah tidak sampai ini berbeda dengan daerah di Kota-kota besar. Sehingga ini berdampak pada jumlah siswa yang bisa yang lolos seleksi untuk tahap Provinsi (KSMP). Ini berdampak peserta yang masuk tingkat Provinsi hanya dari Kota-kota besar saja.(Kemendikbud, 2020)

Pengetahuan para siswa yang antusias untuk mengikuti KSM hanya sebatas materi buku sekolah terkhusus untuk sekolah-sekolah yang berada cukup terpencil padahal tidak menutup kemungkinan disana terdapat siswa yang memang potensi untuk menjadi juara di Olimpiade Sains Sisawa hanya saja mereka tidak mendapatkan pelatihan untuk mempersiapkan diri menghadapi konpetisi sains.

Soal-soal yang dikembangkan pada KSN khususnya kimia terdiri dari 3 kategari dan memiliki strategi dalam pemecahannya. Kategori yang pertama, materi yang terdapat pada materi-materi kimia di SMA kelas X, XI dan XII. Kategori kedua, materi kimia dasar yang merupakan kelanjutan dari materi-materi kategori satu hanya saja tingkat pemahamannya sudah lebih tinggi jika dibandimgkan dengan kategori pertama. Dan kategori ketiga, yaitu materi kimia yang aplikatif yang memerlukan pemahaman tingkat tinggi yang diambil dari materi kategori satu dan kategori dua.(Kurniawati et al., n.d.)

Salah satu model pembelajaran yang dapat meningkatkan kemampuan siswa dalam memahami materi materi olimpiade adalah dengan menggunakan model pembelajaran ATM yaitu amati, tiru dan modifikasi. Dengan menggunakan model ini siswa lebih aktif dalam menyelesaikan setiap soal-sola yang diberikan. Tahap awal siswa diminta untuk mengamati bagaimana cara penyelesaian suatu masalah yang disampaikan oleh Narasumber kemudian tahap kedua siswa diminta untuk dapat menirukan cara penyelesaian masalah yang telah diamati sebelumnya dan pada tahap ke tiga siswa diminta menyelesaiakn soal-soal yang telah dimodifikasi dengan cara yang telah dipahami pada tahan satu dan dua. Pelatihan melalui pembinaan siswa dalam mengikuti olimpiade akan meningkatkan pengetahuan, keterampilan dan kemampuan menganalisis soal bagi siswa. (WIYOKO et al., 2019)

Berdasarkan permasalahan diatas peneliti berinisiasi untuk memberikan "Pembekalan dan Pelatihan Siswa SMA Plus Penyabungan Mandailing Natal Untuk Menghadapi Kompetisi Sains Nasional (KSN) Bidang Kimia Dengan Menggunakan Model Pembelajaran ATM (Amati, Tiru, dan Modifikasi).

Adapun yang menjadi tujuan dari kegiatan pengabdian masyarakat ini diharapkan dapat :

1. Melatih para siswa dalam menguasai strategi-strategi dalam menghadapi soal-soal KSM kimia.

2. Memberikan pemahaman tingkat kategori kesulitan soal olimpiade kepada siswa pada seleksi tingkat Kabupaten.

3. Melatih para siswa dalam menyelesaiakan soal-soal KSM kimia dalam bentuk pilihan ganda

4. Melatih para siswa dalam menyelesaikan soal-soal KSM kimia dalam bentuk essay test.

5. Memberikan masukan kepada guru bidang studi kimia di sekolah SMA Plus Penyabungan untuk memberikan soal-soal latihan yang relevan dengan soal-soal olimpiade.

\section{B. METODE PELAKSANAAN}

\section{Persiapan Panitia}

Persiapan kegiatan Pelatihan dan Pembekalan Menghadapi OSN kimia Bagi 
Siswa SMA Plus Penyabungan Mandailing Natal dilakukan dengan kegiatan sebagai berikut:

a. Koordinasi dengan Kepala Sekolah dan guru bidang studi kimia SMA Plus Penyabungan Mandailing Natal.

b. Meminta izin ke Kepala Sekolah Untuk Pelaksanaan Kegiatan Pengabdian Masyarakat.

c. Mengatur jadwal pelaksanaan kegiatan dengan berkoordinasi dengan pihak sekolah.

\section{Pelaksanaan Kegiatan}

Berikut ini kami laporkan pelaksanaan penyelenggaraan kegiatan Pelatihan Menghadapi KSN Kimia tingkat Kabupaten/Kota SMA Plus Penyabungan.

3. Peserta

Peserta pelatihan ini adalah siswa SMA Plus Penyabungan. Dimana peserta diwakili oleh 5 siswa kelas X IPA dan 5 siswa kelas XI IPA. Yang nanti nya para peserta akan menjadi perwakilan sekolah untuk mengikuti Olimpiade Sains Nasional Tingkat Kabupaten Bidang Studi Kimia. Pemilihan peserta ini diharapkan nantinya akan terjadi regenerasi siswa pada bidang kimia untuk olimpiade tahun yang akan datang. Nama- nama siswa yang ikut dalam kegiatan pengabdian masyarakat adalah sebagai berikut :

\begin{tabular}{|c|l|c|}
\hline No & \multicolumn{1}{|c|}{ Nama Siswa } & Kelas \\
\hline 1 & Yendi Dwi Agusta Putri & XI \\
\hline 2 & Dewi Putri Br Tarigan & XI \\
\hline 3 & Fenita Devana Yosandri & XI \\
\hline 4 & Zulfi Akbar Harahap & XI \\
\hline 5 & Aderia D Damanik & XI \\
\hline 6 & Ribka Martauli Simbolon & $\mathrm{X}$ \\
\hline 7 & Putri Alvanisa Saragih & $\mathrm{X}$ \\
\hline 8 & Aulia Hanim & $\mathrm{X}$ \\
\hline 9 & Andres Tarigan & $\mathrm{X}$ \\
\hline 10 & Ahdilla Putri & $\mathrm{X}$ \\
\hline
\end{tabular}

\section{Jadwal Kegiatan}

Pelaksanaan kegiatan pelatihan berlangsung selama 4 hari yang diawali dengan sambutan dari Kepala sekolah. Pelaksanaan kegiatan terbagi dalam dua sesi, dengan alokasi waktu masing-masing sesi 3 jam. Dimulai dari hari Kamis, 11 - 14 Maret 2021. Tiap sesi disajikan pemaparan materi, pemberian contohcontoh penyelesaian soal-soal KSN dan kemudian dilanjutkan latihan menyelesaikan soal-soal kSN oleh siswa dengan didampingi oleh Tim Pengabdian.

\section{HASIL DAN PEMBAHASAN}

Rincian kegiatan dari pengabdian masyarakat setelah jadwal kegiatan disepakati dengan pihak sekolah adalah sebagai berikut: Model Focus Group Discussion (FGD) dimaksudkan agar siswa tidak jenuh, maka perlu adanya variasi dalam pelaksanaan pembinaan OSN. Selain itu, melalui kegiatan Focus Group Discussion (FGD) mampu meningkatkan kemampuan dan keterampilan dalam pembelajaran. (Siregar, 2018) 


\section{Hari Pertama: Senin, 11 Maret 2021}

Uraian kegiata pada hari pertama pelaksanaan Pengabdian Masyarakat di SMA Plus Penyabungan Mandailing Natal adalah sebagai berikut:

1. Sambutan Kepala Sekola (07.45 -08.00)

2. Sesi I (08.00 wib - $11.00 \mathrm{wib})$

Sesi I disampaikan materi tentang "Strategi Pemecahan Masalah Soal- Soal Olimpiade Kimia Pada Materi Stoikiometri beserta contoh-contohnya" yang disampaikan oleh Efrizal Siregar, M.Pd. Materi ini berisi tentang: konsep mol, massa molar, rumus empiris, dan penyetaraan reaksi.

3. Sesi II (13.00 wib - 16.00 wib)

Sesi II disampaikan materi tentang "Strategi Pemecahan Masalah Soal- Soal Olimpiade Kimia Pada Materi Larutan 1 beserta contoh- contohnya" yang disampaikan oleh Yusnia Sinambela, S.T., M.T

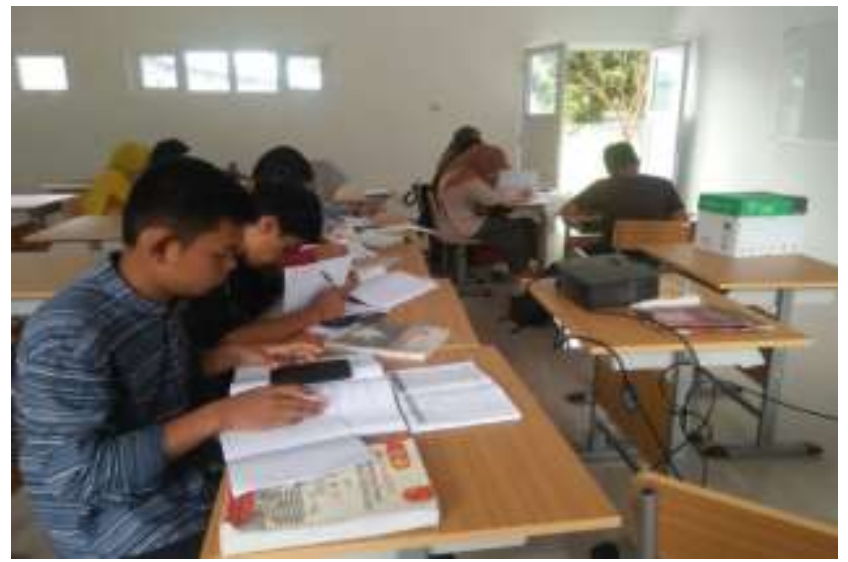

Gambar 1. Kegiatan Diskusi dengan Peserta Hari 1

\section{Hari kedua, Selasa, 12 Maret 2021}

Uraian kegiata pada hari kedua pelaksanaan Pengabdian Masyarakat di SMA Plus Penyabungan Mandailing Natal adalah sebagai berikut:

1. Sesi III $(08.00-11.00)$

Sesi III berisi materi tentang "Strategi Pemecahan Masalah Soal-Soal Olimpiade Kimia Pada Materi Larutan 2 beserta contoh-contohnya" yang disampaikan oleh Efrizal Siregar, M.Pd. Materi ini berisi tentang: Larutan Penyangga.

2. Sesi IV (13.00 - 16.00)

Sesi IV berisi materi tentang "Strategi Pemecahan Masalah Soal-Soal Olimpiade Kimia Pada Materi Larutan 3 beserta contoh-contohnya" yang disampaikan oleh Yusnia Sinambela, S.T., M.T. Materi ini berisi tentang: Hidrolisis Garam.

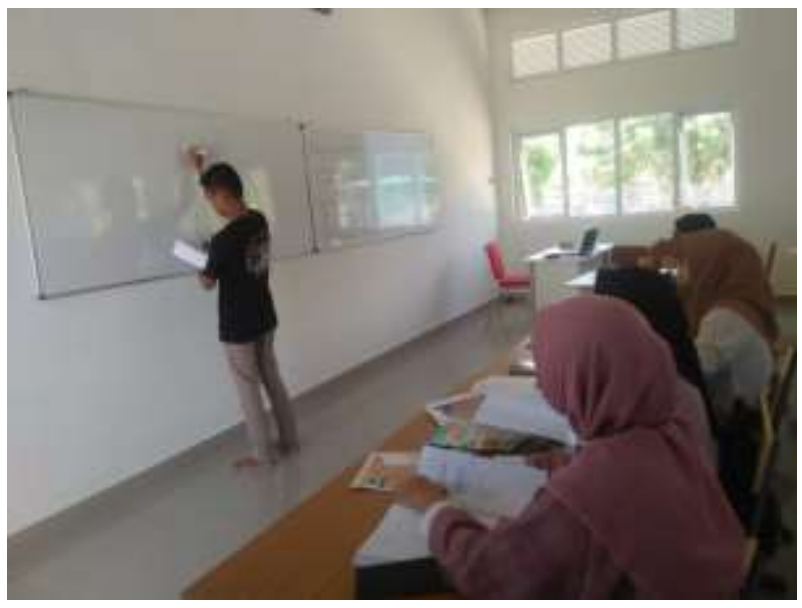




\section{Hari ketiga, Rabu 13 Maret 2021}

Uraian kegiata pada hari kedua pelaksanaan Pengabdian Masyarakat adalah sebagai berikut:

1. Sesi V $(08.00-11.00)$

Sesi Vberisi materi tentang "Strategi Pemecahan Masalah Soal-Soal Olimpiade Kimia Pada Materi Elektrokimia beserta contoh-contohnya" yang disampaikan oleh Efrizal Siregar, M.Pd. Materi ini berisi tentang: sel volta dan sel elektrolisis.

2. Sesi VI (13.00 - 16.00)

Sesi VI berisi materi tentang "Strategi Pemecahan Masalah Soal-Soal Olimpiade Kimia Pada Materi Sifat Koligatif Larutan beserta contoh-contohnya" yang disampaikan oleh Yusnia Sinambela, S.T., M.T. Materi ini berisi tentang: Larutan elektrolit dan nonelektrolit

\section{Hari Keempat, Kamis 14 Maret 2021}

Uraian kegiata pada hari ke-empat pelaksanaan Pengabdian Masyarakat adalah sebagai berikut:

1. Sesi VII (08.00 - 11.00)

Sesi VII berisi materi tentang "Strategi Pemecahan Masalah Soal-Soal Olimpiade Kimia Pada Materi Laju Reaksi beserta contoh-contohnya" yang disampaikan oleh Yusnia Sinambela, S.T., M.T

2. Sesi VIII (13.00 - 16.00)

Sesi VIII berisi materi tentang "Strategi Pemecahan Masalah Soal-Soal Olimpiade Kimia Pada Materi Energetika Kimia beserta contoh-contohnya" yang disampaikan oleh Efrizal Siregar, M.Pd. Materi ini berisi tentang: Hukum Termodinamika

3. Penutup (16.00 - 16.15)

Kegiatan akhir adalah penutup yang disampaikan langsung oleh kepala sekolah dengan ucapan terima kasih dan berharap kerjasama ini terus terjalin di masa mendatang.

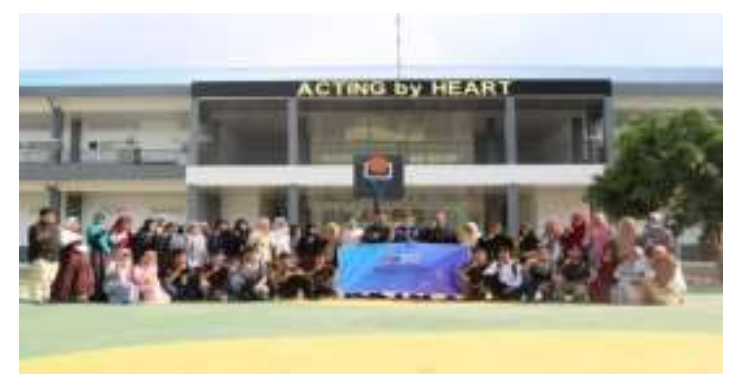

Gambar 3. Foto Bersama setelah Penutupan Kegiatan

\section{SIMPULAN DAN SARAN}

Kinerja Puslitbang dan PPM ini sangat membantu pemerintah dan masyarakat dalam meningkatkan pengetahuan, keterampilan dan perekonomian. Kegiatan pengabdian dan penelitian ini diharapkan mampu menjadi solusi dalam peningkatan sumber daya yang ada. Dengan diadakannya stahun sekali penelitian dan pengabdian masyarakat oleh perguruan tinggi secara internal sangat membantu untuk program-program pemerintah untuk meningkatkan sumber daya manusia yang salah satunya adalah meningkatkan keterampilan dan pengetahuan siswa dalam mempersiapkan diri untuk mengikuti KSN Tahun 2021. Sehingga nantinya peserta dapat memperoleh medali setelah mengikuti OSN tersebut. Untuk itu, pengabdian ini tentu harus dilakukan oleh tim pengabdi yang memiliki kemampuan dan kelayakan yang memadai 
12 | PEKAMAS (Pengabdian Kepada Masyarakat) | Vol. 1, No. 1, Juli 2021, hal. 7-12

\section{UCAPAN TERIMA KASIH}

Penulis mengucapka terimakasih kepada Bapak Hendrik,M.Pd sebagai kepala Sekolah, yang memberikan kesempatan kepada Tim Penulis dalam melaksanakan pengabdian Kepada Masyarakat dan semoga melalui kegiatan ini SMA Plus Penyabungan Mandailing Natal mendapatkan prestasi/medali setelah mengikuti KSN Tahun 2021.

\section{DAFTAR RUJUKAN}

Kemendikbud. (2020). Pedoman Kompetisi Sains Nasional Sekolah Menengah Atas. https://id.wikipedia.org/wiki/Sekolah_menengah_atas.

Kurniawati, M., Fisika, D. P., \& Malang, U. K. (n.d.). Maris Kurniawati, Dosen Pendidikan Fisika Universitas Kanjuruhan Malang 446. 446-455.

Siregar, S. (2018). Meningkatkan Kemampuan Guru Dalam Menerapkan Pembelajaran Kontekstual Melalui Focus Group Discussion (Fgd) Di Smk Negeri 1 Sirandorung Tahun Pelajaran 2017/2018. NUSANTARA : Jurnal Ilmu Pengetahuan Sosial, 5(1), 14. https://doi.org/10.31604/jips.v5i1.2018.14-19

WIYOKO, T., Megawati, M., Aprizan, A., \& Avana, N. (2019). Peningkatan Kompetensi Siswa Melalui Pembinaan Olimpiade Sains (Osn). Warta LPM, 22(2), 67-75. https://doi.org/10.23917/warta.v22i2.8619 